\title{
Framing climate change in frontline communities: anthropological insights on how mountain dwellers in the USA, Peru, and Italy adapt to glacier retreat
}

\author{
Ben Orlove ${ }^{1}(\mathbb{D}) \cdot$ Kerry Milch $^{2} \cdot$ Lisa Zaval $^{3} \cdot$ Christoph Ungemach ${ }^{4} \cdot$ Julie Brugger $^{5} \cdot$ Katherine Dunbar $^{6}$. \\ Christine Jurt ${ }^{7,8}$
}

Received: 17 January 2018 / Accepted: 25 February 2019 / Published online: 7 May 2019

(C) The Author(s) 2019

\begin{abstract}
We report on anthropological research conducted in three mountain communities (in the USA, Italy and Peru), which have been directly affected by glacier retreat for over 40 years. Our mixed methods include ethnographic research, analysis of transcripts of interviews, focus groups and community meetings, and case studies of adaptation projects. Our findings indicate that local people are acute observers of change. They draw on two frames (climate change and community) in their discussions and projects but rely much more heavily on the latter frame. This pattern of drawing on the community frame, characteristic of all discussions, is most marked in the community meetings. The effectiveness of the community frame in supporting projects calls into question some widely shared notions about the role of belief in climate change as a crucial precondition for adaptation and challenges the "perceive-predict-act" model of climate change response.
\end{abstract}

Keywords Climate change communication · Adaptation · Framing $\cdot$ Community $\cdot$ Glacier $\cdot$ Cryosphere $\cdot$ Anthropology

\section{Introduction}

Society's incomplete and slow response to climate change has led many to seek explanations for this limited level of action.

Electronic supplementary material The online version of this article (https://doi.org/10.1007/s10113-019-01482-y) contains supplementary material, which is available to authorized users.

Ben Orlove

bso5@columbia.edu

Kerry Milch

kmilch@psych.columbia.edu

Lisa Zaval

lisazaval@gmail.com

Christoph Ungemach

christoph.ungemach@tum.de

Julie Brugger

jvbrugger@gmail.com

Katherine Dunbar

katsdunbar@gmail.com

Christine Jurt

christine.jurt@geo.uzh.ch
Within the extensive literature on this subject, two lines of explanation have received a good deal of attention. The first suggests that climate change does not motivate people to act because it is hard to perceive. Many discussions of the topic
1 Center for Research on Environmental Decisions, and School of International and Public Affairs, Columbia University, New York, NY 10027, USA

2 Center for Research on Environmental Decisions, Columbia University, New York, NY 10027, USA

3 Center for Research on Environmental Decisions, and Department of Psychology, Columbia University, New York, NY 10027, USA

4 TUM School of Management, Technical University of Munich, 80333 Munich, Germany

5 School of Natural Resources and the Environment, The University of Arizona, Tucson, AZ 85721, USA

6 Center for Integrative Conservation Research, University of Georgia, Athens, GA 30602, USA

7 Department of Geography, University of Zurich, 8057 Zurich, Switzerland

8 School of Agricultural, Forest and Food Sciences, Bern University of Applied Sciences, 3052 Zollikofen, Switzerland 
emphasize impacts that occur in remote places or that are forecast to unfold in the future. As a result, climate change is seen as distant in space and in time, and as involving probabilities rather than certainties (Weber and Stern 2011), features which have been termed "dragons of inaction" because they create doubt and remove the urgency from addressing climate change (Gifford 2011).

A second line of explanation suggests that climate change does not motivate people to act because it is hard to comprehend. Climate change results from invisible substances (greenhouse gases) which operate through complex causal pathways (Weber and Stern 2011). Many people are unfamiliar with the technical terms and research methods which are central to scientific accounts of climate change (Pidgeon and Fischhoff 2011). As a result, climate change science is confusing for many, leading to mistrust of science, another "dragon of inaction" (Reynols et al. 2010; Guy et al. 2014).

Taken together, these two lines of explanation form what has been called the "perceive-predict-act" approach to climate change adaptation (Findlater et al. 2018). This approach draws on studies such as the research in the US Midwest which shows that individuals "who believed that climate change is occurring and attributable to human activity were significantly more likely to express concern about impacts and support adaptive and mitigative action" (Arbuckle et al. 2013: 944).

To examine these accounts of limited perception and understanding as obstacles to actions regarding climate change, we have conducted research in communities where climate change is a visible, long-standing fact: high mountain areas in the Italian Alps, the Peruvian Andes, and the North Cascades in the USA. In all three settings, significant glacier retreat has occurred in recent decades. In these places, the shrinking of glaciers on the highest peaks makes climate change impacts easier to see, and they have become a topic of conversation. In this way, some dragons of inaction often associated with perception - the remoteness of climate change impacts, and the uncertainty whether any impacts are taking place - are less likely to impede responses in these settings. In addition, the residents of these regions have been the recipients of education and communication programs, provided by media, NGOs, and government agencies, which seek to build a scientific understanding of climate change. These programs, often tailored to mountain environments, could make climate change easier to understand by overcoming some aspects of its complexity.

We therefore explore whether the small communities living close to glaciers perceive the retreat and other changes associated with climate change. We consider whether they understand that these changes have occurred as the result of climate change and whether the linkage with climate change is a crucial motivator for action; our research also examines alternative forms of understanding these changes, through accounts that are centered on local society rather than on global climate. Our discussion moves from the spheres of perception and explanation to the realm of action, examining the steps which local people undertake for the betterment of their communities. We pay particular attention to the role of perceptions and explanations in providing motivations for these actions.

\section{Frames for understanding change}

\section{The concept of frames}

A central element of our research is an examination on the ways in which people in high mountain settings understand the changes which they perceive in their environments. We draw on the idea that people tend to form explanations that are part of interrelated systems of beliefs.

Other anthropologists who have conducted ethnographic research on climate change share this idea, using a variety of terms for these systems. Crate, discussing the Sakha herders of Siberia, speaks of "cultural models" which people use to "frame the local effects of global climate change" (2008: 574). Sherpa refers to the "knowledge systems" (2014: 158) which organize the narratives through which Sherpas in the Mount Everest region of Nepal explain their perceptions and experiences. Lipset, writing of coastal communities in Papua New Guinea, draws on Bakhtin's notion of "chronotope," which he defines as "a category or unit of analysis that constitutes and organizes the meaningful ordering of events in the space and time of narrative texts" (2011: 21). McQuaid et al. discuss the "narrative frames" which residents of a provincial city in Uganda use as they "ma[k]e sense of a changing climate" (2018: 12).

While recognizing these different terms, we follow McQuaid et al. and others in using the word "frame," a concept with a long history in social science (Goffman 1974). Tversky and Kahneman (1981) use the term to show that people make judgments and select actions based on their understandings of the situations in which they find themselves at any given moment. As recently noted (Fløttum and Gjerstad 2017), frames serve to construct narratives which can guide action. They focus attention on certain features of the social and natural world and hence away from others; without such filters, the amount of information to be considered would be too large for any individual or organization to manage.

\section{Interacting frames in ethnographic research}

Anthropologists who study climate change have noted that specific communities often use multiple frames, rather than only one frame, to explain the impacts of climate change and to formulate responses. These frames include longestablished accounts, whether based on local cultures or major 
religious systems such as Islam or Buddhism, or on the newer cosmopolitan approach of climate change science and policy. The former can be broadly associated with the community frame which we describe in our three cases; the latter, though differing in some details, correspond to the climate change frame.

Khan's account of a riverine island in Bangladesh shows that local residents account for floods, which are growing more frequent and severe, through their particular form of Islam. These interpretations explain moments of good fortune and misfortune and indicate the responsibilities of humans to each other and to other beings in such circumstances (Khan 2014a). The residents are aware of a cosmopolitan frame of disaster risk reduction linked to climate change and participate in NGO-based programs that draw on it. However, they do not accept it as a system of explanation. Khan indicates that the residents maintain a firm distance from it: at a moment after the NGO personnel had departed from the village, they mocked it in a parodic recitation (Khan 2014b).

Lipset discusses two chronotopes (analyses which organize and order events across time and space) that populations in a river delta in coastal Papua New Guinea use to account for sea level rise. Lipset terms these a modernist global risk view, presented by local men who have achieved high office in the national government, in which the danger is severe, and determined by human action around the world, and a magical view, centered on ancestral masculinity, more broadly voiced in the village, in which the more limited threat, caused by local action, can be effectively addressed. These chronotopes differ significantly in the role of human action as cause and as potential response. Lipset sees a different relation between them than in Bangladesh, noting that, for some individuals at least, it is difficult to reconcile these two views: he discusses a man whose "simultaneous acknowledgement of, and plain scepticism about, global warming summed up the ambivalence with which he and others viewed the present in this chronotope" (2011: 39). This might be called a cautious coexistence; though, like the Bangladeshis, they retain long-established understandings and practices, they also give some hesitant assent to the climate change frame, at least in certain contexts.

In some other cases, older local and newer cosmopolitan frames can combine and even merge. Discussing the Marshall Islands, Rudiak-Gould describes this combined frame as a "reinterpretation" of the cosmopolitan frame, circulated by local leaders; he states that the "Marshallese view of climate change as a hybrid sociocultural/environmental risk emerges as a wholly reasonable, and indeed insightful and sorely needed, framing of the issue." (2012: 53) This combination is reported from other settings as well. Crate's discussion of Sakha pastoralists in northeastern Siberia presents the results of some of the earliest ethnographic research into climate change, conducted in the opening years of this century. Moreover, she reports on a relatively isolated area, but even in that setting and at that time, people occasionally draw on images from television accounts in their descriptions of changing seasonal patterns (2008: 681), as they seek to make sense of the failures of their long-established and deeply held cultural models; these efforts seem much more tentative than the sustained engagement that led to the development of a hybrid frame in the Marshall Islands.

Sherpa's study in Nepal, based on research in a number of different villages in the Mount Everest region, reports a complex pattern, in which the frames differ by gender, age, and location (2014a). Some individuals, particularly young men in villages located along major tourist trekking routes and with extensive NGO engagement, are familiar with the climate change frame and draw on it to explain environmental changes and extreme events. Others, particularly in more isolated villages, emphasize long-established Buddhist cosmologies, which attribute natural disasters, including those associated with climate change, to improper behavior and to lack of religious faith; they were uncertain about the causes of warmer temperatures and reduced snowfall, though some thought that these might be natural processes. A number of these people try to avoid exposure to the climate change frame, because they find that it is nomdok (inviting misfortune); its repeated references to floods create anxiety and lead to false rumors of impending disasters (Sherpa 2014b).

As these cases show, engagement with the climate change frame can be more complex than is suggested by the commonly cited polar opposites, in which individuals either believe in it or reject it in acts of denial or skepticism. Some, like the Marshallese, combine it with other beliefs; others, like the coastal peoples in Papua New Guinea, consider it with some uncertainty. In other cases, people overtly mock it, as in Bangladesh, or draw on elements of it rather than taking it on whole, as the Sakha do. Moreover, engagement with the climate change frame is not only an engagement with the propositions it contains and the evidence it offers for them. It is also an engagement with the sources of those propositions, with the newer climate change frame linked with external organizations and the longer-established frames associated with local elders and authorities. The participation of local leaders in the climate change frame, as in Papua New Guinea and the Marshall Islands, can lead to the adoption of this frame, though, as these two cases show, that process is not automatic or uniform.

In our research in three sites, we examine the two cognitive frames which we have found in our sites. These are the climate change frame and the community frame, which individuals use when discussing the issue of glacial retreat. We see as well that engagement with these two frames is more complex than a simple matter of belief in or rejection of climate change tout court.

The climate change frame emphasizes that human action takes place in the context of a changing global climate and is grounded in the language of environmentalism. This frame 
recognizes increased temperatures and an increased frequency of extreme weather events as worldwide phenomena that are the result of increased greenhouse gas emissions. It sees these shifts as creating many negative impacts, some of them unprecedented, on human societies and natural ecosystems. It anticipates that these impacts will increase in extent in coming decades, though specific details about these impacts are uncertain. The climate change frame emphasizes a "we" of humanity that has created an unparalleled global problem. To develop responses to these impacts, it draws on concepts of mitigation at global scales and adaptation at national and local scales. This problem can only be solved permanently at a global scale, though it admits many responses at smaller scales.

In contrast, the community frame emphasizes that human action takes place in the context of ongoing local societies. Key aspects of these societies include multi-year and multigenerational residence, frequent interactions between neighbors, and participation in local governance. The community frame locates these societies and organizations in the context of local environments and of national economics and politics and considers environmental changes through their relations with and impacts on local societies. It recognizes that societies in remote rural areas occupy a marginal position within national politics. The community frame emphasizes a "we" of local societies. It recognizes a variety of positive opportunities and negative challenges in regional and national contexts, both in past history and in possible futures. Residents can address challenges and take advantage of opportunities, drawing on core values of local society (the strength of local identity, the importance of local self-reliance) and mobilizing their social ties and local organizations.

The following sections present the research sites and specific responses to impacts of glacier retreat in each and provide quantitative and qualitative analysis of a large body of conversations which we recorded in these sites. We show that the residents, though aware of the climate change frame, rely much more extensively on the community frame, using it to construct and carry out responses to the changes which they see in their environment.

\section{Research sites and methods}

We present brief descriptions here of the three research sites. Fuller descriptions can be found in Online Resource A.

The US site consists of two towns in Washington State, Concrete and Glacier, with a combined 2010 population of 916. They are located on the slopes of Mount Baker (3286 m) in the North Cascades, the most densely glaciated mountains in the contiguous USA. The glaciers, rivers, lakes, and snowpack support winter and summer recreational activities. Settled in the nineteenth century, the towns were initially dependent on logging and on the production of cement, though these activities have largely ended. Recreation tourism is the major source of income, supplemented by wage income from employment in nearby urban areas. There is a large hydroelectric power facility close to Concrete, but it has few local employees.

The Italian site is made up of three villages, Trafoi, Stilfs, and Sulden, in northern Italy on the border with Switzerland and Austria. The total 2011 population is 1190 . They are located on the slopes of Ortles (3905 m), one of the highest peaks in the eastern Alps. Following the collapse of the mining industry in the eighteenth century and farming in the nineteenth century, the region shifted to tourism as a major source of income. Though historically part of the Tyrol in Austria, the region passed to Italy after World War I, later receiving the status of an autonomous province. It remains strongly German-speaking,

The Peruvian site is a village, Copa, composed of seven sectors or hamlets, with a total 2007 population of 1339 . It shares its name with the mountain on whose slopes it is located: Copa (6188 m), a peak in the Cordillera Blanca, the largest area of tropical glaciers in the world. Agriculture and livestock raising are the major economic activities, as they have been for centuries. In recent decades, they have been supplemented by remittances from kin in Peru's capital city of Lima. The area experienced significant disruptions in the 1970s, with a major earthquake and a significant agrarian reform program. The residents speak Quechua, an indigenous language, and many are bilingual in Spanish as well.

These three sites share a significant reliance on livelihoods (agriculture, tourism) that are based on local resources and are located on lands which they own; they also rely strongly on local governance institutions to manage their affairs. In the second characteristic, and to some extent the first, they differ from other sites of recent anthropological studies of climate change in glacier regions, including Sherpa's work in Nepal, discussed earlier. Rasmussen (2015) reports on a set of communities about $50 \mathrm{~km}$ southeast of Copa in the Cordillera Blanca, with greater involvement with the Peruvian national government than in Copa. The agrarian reform brought a series of conflicts to this region and led to continued attention of the government in it. The communities have sought state support to construct a series of canals which transport water between different drainages and protested state plans to allow mines to operate in the area, threatening diversion and pollution of a major river. Rasmussen suggests that "state abandonment" is a key frame for the community members, since they seek closer ties and more support from the state. Mendoza (2018) discusses the remote Argentine region of Patagonia, where mountain tourism, centered on climbing and trekking, has boomed since the 1990s, largely displacing the remnants of the livestock-raising estates that earlier characterized the region. National parks control much of the prime sites for visitors, and the negotiations between different groups-tourists, the owners and workers in tourist 
enterprises, researchers, and land managers-are influenced by changing national policies of land management and tourism development. Mendoza indicates that "green productivism"- a version of sustainable development-is the key frame for the people in the region, since they see considerable promise in the expansion of ecotourism. Gagné (2019) examines Ladakh in the arid western Himalayas of India. The Ladakhi are Buddhist and speak a Tibetan language. Their traditional agricultural livelihoods face difficulties from decreasing water supplies and also from the transformation of the region by the presence of the Indian state. Lying close to the border with Pakistan, Ladakh has seen a large expansion of military facilities and state involvement in local governance. In- and out-migration have grown significantly. Gagné discusses Tibetan Buddhist ethics as a key frame for the Ladakhis, who seek to restore a moral order among people, deities, and the natural world, in contrast to Indian notions of state-led national development.

As indicated above, these other sites differ from the ones discussed in this article because of the greater state control of productive lands (granting mineral concessions in Peru, tourism sites in Argentina and Nepal, military facilities in India) and the stronger presence of state institutions in local affairs. Nonetheless, they have a broad resemblance to the three sites in this paper, since their dominant frames focus on community, though with tighter articulation with the national state (affiliation with the state in Peru, alignment with the state in Argentina, accommodation to the state in India in Nepal). The climate change frame, though somewhat more salient than in the sites in this article, remains of secondary importance.

Our research at all three sites was conducted using two sets of methods. Firstly, the field researchers in the team (JB, KD, CJ), following earlier visits to the research regions, conducted ethnographic and historical research in the sites for periods of 1017 months; follow-up visits to all three sites have been carried out in recent years. Secondly, we assembled a dataset of three sorts of conversations: (1) in-depth interviews, in which one interviewer spoke with a community resident; (2) focus groups, in which one researcher facilitated discussion by a group of community residents; and (3) analysis of records of community meetings. For the first two, we recorded and transcribed the conversations; for the third, we accessed the detailed minutes of meetings, recorded by participants. These methods are discussed more fully in "Mixed methods: qualitative and quantitative analysis of conversations," below. See Online Resource B for a table of demographics and information on conversation types and a fuller description of the research methods.

\section{Community responses}

To assess the importance of the two frames in these settings, we draw on our ethnographic research as well as the recorded conversations to discuss three specific cases of collective activities, undertaken by the communities. The cases are ones that could plausibly be considered from the community frame (because of the scale of action) and from the climate change frame (because the focus of action is a sector impacted directly by glacier retreat.) The cases were selected to represent a significant level of engagement (lasting for at least 5 years and involving the participation of a significant number of local residents).

In the discussion of each, we open with a discussion of a specific impact of glacier retreat, trace the history of the impacted sector and the local response, and then draw on representative actions and comments to show the importance of the two frames. We find that the community frame is the dominant one in all three cases. In the discussion section, we suggest that these actions can be classified as adaptations, though they do not fit precisely with standard definitions of the term.

\section{Washington State: community festivals}

In the towns of Concrete and Glacier, glacier retreat has had negative consequences for tourism, since ice and snow have constituted the major attractions. The Mount Baker ski area, which dates back to the 1930s, brings large numbers of visitors. It has one of the longest ski seasons in the region, both because of the heavy snowfall it receives and because the glacier surfaces retain snow more effectively than rock or soil. Mount Baker supports summer skiing as well, drawing people who hike up on the glaciers or reach them by helicopter and snowmobile. Moreover, the glaciers are an attraction for summer visitors, whether they wish simply to view them or to hike up to or on them. Mount Baker contains the lowest elevation permanent ice in the contiguous USA, making it an important site for recreational ice climbers. Glacier retreat thus threatens the cryosphere tourism that has been central to the local economy for decades.

In this context, the steps that the towns have taken to create and expand festivals which draw tourists to other attractions, including historical heritage and wildlife, could be seen as responses to glacier retreat. These festivals have been presented by both frames, but the community frame is the more frequently mentioned.

The oldest of the festivals, Cascade Days in Concrete, dates back to 1934, when townspeople established it to promote highway construction over the crest of the Cascades. It has been held every year in August since then and expanded in recent years with support from a community nonprofit organization, the Imagine Concrete Foundation, established in 2011.

The North Cascades Vintage Fly-In, founded in 1983, attracts vintage plane owners and fanciers to the municipal airport in Concrete each July. It, too, has grown recently, when meetings with the Concrete City Council addressed the issues 
of revenue-sharing and noise that had created some local opposition. The Skagit Eagle Festival, first held in 1987, brings visitors to Concrete and other towns each January to view the large concentrations of bald eagles, attend events centered on wildlife, and engage in activities centered on local heritage, including hayrides and Native American storytelling. In addition, other festivals and events have been established more recently: since 2006, there has been a weekly Ghost Walk through the Concrete town center in October. Glacier has two events as well, established in both the last decade by the Mount Baker Chamber of Commerce: Glacier Days in August and a popular bicycle race in September from Glacier to the Mt. Baker Ski Area. All of these events are run by local volunteers, who coordinate with town authorities.

In the interviews, a few people raised climate issues when discussing snow- and ice-based recreation, though they did not use a climate change frame. One linked tourism to weather and to climate variability, saying, "Good snow accumulation brings a lot of tourists up here, which provides money to support local people who work at these places." This statement reflects the fact that snow amounts vary significantly from year to year in this region, which is strongly affected by El Niño and La Niña events. Another resident mentioned long-term trends, rather than short-term fluctuations, but stressed their impact on intergenerational continuity, rather than talking about climate: "Skiing is such a huge part of my life. And I'm getting older, but for my kids, it's a major part of their lives and I hope that they'll be able to continue to ski. Maybe they won't be able to for their whole life."

In general, local residents emphasized the importance of supporting and expanding tourism. They couched this concern through a community frame, supporting livelihoods and intergenerational continuity, rather than through a climate change frame of adaptation and response to glacier retreat. One stated, "These kids who get out of high school, there's not much for them to do except go out of town and find a job in [the nearby town of] Mount Vernon or Seattle. Some of them of course go to college, but probably the majority of them don't. So there's no real way to make a livelihood up here. We're dependent on tourism." They trace the link between festivals and tourism. "We rely quite heavily on tourism. People come up to go hiking, they come up to go hunting, people come up to go eagle watching in the winter."

However, the tourists were also mentioned as a kind of nuisance tolerated by locals, even though they interfere with daily life: "We always joke about the eagle watchers. They stop in the middle of the road and look at the eagles. They see this small [two-lane] Highway 20 and they don't think of it as being a major highway."

Other people mentioned Cascade Days, not in terms of income and livelihoods, but as part of community social life. Some note that it provides an occasion for former residents to return to visit. One said, "We have a reunion here in the yard for Cascade Days. I usually get about eight of our classmates to come home." Another mentioned a local musician who plays in a country music band which performs around the state and comes for Cascade Days. Others see the festival as an expression of community spirit. The organizer of the book sale that supports Cascade Days described the sale as follows: "Every day we have opportunities to be part of a miracle. I realize how corny that sounds to many people, but I truly believe that. The planning, organization, and execution of Cascade Days is a prime example. Such community activities simply would cease to exist without the numerous volunteers who step forward. I am amazed by the number of people willing to give their time."

In sum, residents of both Concrete and Glacier are actively involved in community organizations and activities. The festivals are one element of these efforts. The residents do not discuss the winter or summer festivals through a climate change frame, as responses to cryosphere processes like glacier retreat, but rather through a community frame, as ways to support livelihoods, maintain awareness of the past, retain young people, and draw out-migrants back.

\section{Italian Alps: wood chip plants}

Glacier retreat has had negative consequences for energy production in Stilfs, which has long relied on local hydropower plants for electricity. The flow in the rivers is lower, reducing the plants' generation capacity. It has also become more unreliable, since it has been interrupted more frequently by debris flows, also associated with glacial processes. The debris flows increase the sediment load to a level which could damage the hydroelectric facilities, requiring temporary closures or reduced production as the water flows through settling basins. Moreover, demand for electricity, particularly in the tourism sector, has been increasing, due in part to climate change; resorts have smaller areas of glaciers which can be used for skiing, and the snow season is becoming shorter. As a result, the resorts use snow machines, which require a great deal of electricity to operate.

One of the steps that the local electricity provider has taken to address this deficiency of hydropower capacity is the installation of biomass generation using wood chips. Residents have discussed these facilities using both the climate change and community frames, but the community frame is presented more often.

In this context, the Stilfs Electricity Cooperative (Elektrizitätswerk Stilfs Genossenschaft) is the key organization at the local level. The earliest hydropower plants in the area were very small ones, set up by hotels to serve their guests. A cooperative, established by a local priest in 1921, just 2 years after the region passed from Austria to Italy, expanded production significantly and provided service to local residents. The Italian government under Mussolini sought to 
expand electricity production in the region, to export electricity to other regions, and to promote local industrialization as a means of attracting Italian-speaking migrants to this Germanspeaking region. The cooperative maintained its autonomy, though the national government built other power plants in the region and expanded the grid which linked them. Postwar governments also sought to increase energy production through the creation in 1962 of the Italian National Electricity Agency, which acquired regional power utilities throughout the country. It required the Stilfs cooperative to join the national grid, and for a time acquired ownership of the power lines in Stilfs itself. The cooperative itself expanded in the 1970s and 1980s, adding several hydropower plants throughout the community, but regulations on the construction of more plants became more restrictive in the 1990s, as the National Electricity Agency tightened requirements and the national park placed stricter guidelines on land use management.

Biomass plants, used elsewhere in the region, seemed like a positive alternative to increase generation capacity. The first was opened in 2002; others were added in the following years. They burn wood chips, produced locally from lumber mills, from furniture and craft shops and from orchard prunings and small woodlots. Moreover, the biomass plants incorporate systems which pump hot water from the turbines to homes for domestic heating. Firewood, the traditional fuel for home heating, had been partly displaced by heating oil in the decades after World War II; the end of reliance on oil heating was a second reason to promote biomass energy. In addition, subsidies under European Union guidelines for biomass made the electricity less expensive, somewhat offsetting the high initial investment in the plants.

The regional government discussed these plants soon after they first opened, drawing on a mix of climate change and community frames. Its report listed adjectives linked with the former (renewable, carbon-neutral) and with the latter (indigenous (einheimisch), locally available). It also connected biomass with the community frame, indicating that kitchen, farm, and home stoves are "very popular in South Tyrol and associated with centuries of tradition" and adding "The advantages of these [biomass] systems are above all the independence of external energy (electric energy) and in the pleasant warmth in the heated rooms" (AfE 2005: 27).

Though residents occasionally describe wood chips as a renewable energy source, an element of the climate change frame, they draw much more often on the community frame. One stressed the importance of relying on local resources, and of using them efficiently. He stated, "In the winter, we don't have water to make electricity, so we have to use wood chips: they are used twice [for electricity and heating]." He added that if local supplies of wood chips are insufficient, they can be purchased from Austria, with "support and subsidies" from the EU, emphasizing the local economy rather than environmental benefits of shifting from oil for heating. Others note that the pipes which bring hot water to houses can also carry fiber-optic cables to local homes, promoting an additional benefit at low cost, serving both to promote local tourism and to modernize the community, addressing a concern particularly of younger residents.

Locals speak with pride about the long history of the cooperative. One stated, "The cooperative outlasted world wars, fascism and nationalization [through the Italian National Energy Authority]." Others look to the future, indicating that the cooperative brings local independence, setting prices with the members of the cooperative in mind; one even stated that the cooperative, using biomass, would create "lives with futures for young families, and in this way it will stop them from thinking of out-migration."

The chair of the cooperative explained his reason for preferring the biomass generation to purchasing from other firms over the national grid in simple terms. "The money stays here," he said.

\section{Peruvian Andes: new water delivery technologies}

Glacier retreat has had negative consequences for the availability of water in Copa, whose residents have long depended on the Río Allancay, which descends from the Copa glacier, to provide water for irrigation and domestic use. The river's flow used to be abundant, but it has decreased in recent years, as the glacier has receded. Moreover, demand for water has grown. Warmer temperatures and more irregular rainfall have increased the importance of irrigation during both the dry and rainy seasons. Marcará, the town in the valley below Copa, is growing in population, and its residents consume more water as they build larger houses and use more domestic appliances.

In this context of reduced supply and increased demand, the residents of Copa have undertaken steps which address this deficiency of water by shifting to water infrastructure with lower losses through infiltration. They have used concrete to line the earthen canals which convey water from the river, and they have constructed systems to pipe water from the river directly to homes for domestic use. These new technologies have been discussed more frequently through the community frame than through the climate change frame.

Irrigation has long been established in the region, where it allows residents to cultivate a second crop in the dry season, unlike residents in other areas who rely on rainfall alone and raise only one crop a year. Irrigation was an important component of agriculture in Copa during the period of haciendas (private estates), which ended with the Peruvian agrarian reform of 1969.

A major earthquake in 1970 severely damaged the canals. By 1976 , Copa was officially recognized as a peasant community, the collective owner of the former hacienda lands. In one of their first acts, its members restored a major canal 
which diverted water from a high spot on the Río Allancay, carrying sacks of cement, provided by government aid for earthquake reconstruction, up from the valley to line the canal. It provided water to a network of earthen canals. Some additional canals were lined in the following decades, though many remain unlined to the present.

A project to provide one of the seven sectors of the community with domestic water (agua potable) began in 2005 . This sector was a major one, containing two chapels and a schoolhouse. The financing came through the district government of Marcará, which administers Copa; it was paid for by royalties from mining companies in the region. Community leaders presented this project to the district government. At the same time, the district government approved a new domestic water project for Marcará itself. Both of these projects draw water from the Río Allancay above the major diversion for irrigation.

A principal goal of the project was to help Copa Grande gain recognition as a municipality, raising it above the category of caserio (hamlet). As such, it would receive part of its budget directly, rather than applying for each expenditure to Marcará, and would have greater claim on government services. To achieve this status, it needed to document a population of 1000 adults, including other sectors of the community, and also to demonstrate a certain level of urban development, for which domestic water was key (Bobfiglio 2014). It also laid out streets on a grid and mapped house lots, facilitating the provision of piped water.

This status of municipality was granted in 2008. In 2009, a second, cement-lined diversion canal was built from the Río Allancay to serve the lower sectors of the community. Improvements of irrigation continued as well, with cement lining of some secondary canals. These were supported by the National Water Authority, also created in 2009 in conjunction with a new national Water Resources Law. These changes increased the collection of irrigation fees, which, though nominal in amount, were a significant change for Copa, long accustomed to thinking of itself as the owner of its water. The water authority also supported the lining of additional canals, with a significant project in 2015 .

The establishment of the municipality has brought changes, particularly to the central sector, where improvements to education and electrification are concentrated. As a municipality, Copa has been able to solicit road improvement projects, which benefit all the sectors.

For the residents of Copa, water remains of great importance, since the large majority of the population has close ties to agriculture. Though they recognize the importance of glaciers, they view water issues largely through a community frame. Many of them articulate a belief that the final disappearance of the glaciers will mean a complete absence of water, sometimes even suggesting that rains will end. One resident asked, "What water will we live with when the glacier is gone?" Another simply stated, "We will die without water." However, they do not suggest that this dramatic change will occur in the near future.

Some people, especially those served by new canals, speak positively of canals. A woman from one of the lower sectors stated at a focus group, "[In the past] we barely had any water. Ever since the Allancay canal was opened, we've had plenty of water. The canal is like our own river."

Many more comment on the scarcity of water. One man stated in an interview, "There is less water overall now, no more than a fifth comes now. It is not like earlier times, when more came. Now they have taken water with different canals and it does not reach us like it used to." Another noted that the canals removed all the water in the Río Allancay; in 2015, for the first time, it did not discharge any water at its confluence with the Río Vicos below it.

The concerns about water take different forms. Some complain of the decline of the springs in the community, which used to supply domestic water to all the sectors, and served to water livestock as well. One man stated, "The springs have dried up because of the potable water [in the central sector]. There is almost no water coming out of the ground now." Another man indicated that the water that he currently has is sufficient. He indicated that he can afford the fees that he has been paying since 2009 , but he thinks that the state might increase them substantially. "I think that they will, I'm not sure but I believe that sooner or later they will."

Another reported a strong disagreement between his sector, a neighboring one, and a community adjacent to Copa. "We used to be together with them, but now the other sector wants to take away all the water. We can't live like that, with water just for them. What would we eat? There has to be sharing. But they went to the Ministry of Water and bribed them." The other sector arranged for technicians to come, presumably from the Ministry of Agriculture and Irrigation, who spoke in favor of the other sector. Though the other community seems to have stayed on the sidelines, the two sectors had an angry confrontation afterwards, which ended with an arrangement close to previous sharing of the water. "We are all right for the time being. I don't know what it will be like in the future, but now we are sharing and we've left it like that."

Though these comments about water raise many specific issues, they all refer to other social actors-other sectors in the community, neighboring communities, the town of Marcará, and the state - as the source of water scarcity. The domestic water project supported the granting of municipal status to Copa. This status, in turn, has brought new benefits to the community but also created a gap between the municipal center of Copa Grande and outlying sectors. The domestic water project, one of the more visible inequalities, is also blamed for decreased water supplies. As these issues indicate, water availability is considered largely through the community frame. 


\section{Mixed methods: qualitative and quantitative analysis of conversations}

As indicated in the previous section, communities in all three research sites have undertaken actions which could be described as adaptations to climate change, since they address the negative consequences of glacier retreat on resource availability and livelihoods. However, the people who engage in these actions have articulated them through the community frame rather than the climate change frame. This pattern of the use of frames leads back to the questions raised earlier in this paper of whether climate change is difficult to see and difficult to understand.

To assess these matters of perception and comprehension, we examine a body of material from the same communities which complements the analysis of actions. In this section, we report on the analysis of a large corpus of talk within the communities. This material consists of three different types of conversations, all found in all of the communities: (1) indepth interviews, in which one interviewer spoke with a community resident; (2) focus groups, in which one researcher facilitated discussion by a group of community residents; and (3) analysis of records of community meetings. We refer to these as "types of conversation," to emphasize that they all involve people sitting together and talking. The interviews and focus groups were organized around exploratory questions of changes to mountains and glaciers. The meetings had agendas established by local leaders and other community members.

Our analysis rests on the unit of a "turn," defined as the words that one individual speaks without interruption (Enfield 2017: 35-44). We conducted content analysis of this corpus of materials through two complementary techniques, which comprise mixed methods of analysis (Benoit and Laver 2007). The first is based on human judgment, allowing for interpretation of complex issues such as causation, though involving some element of subjectivity; the transcript or record of each conversation was read independently by three trained individuals who noted a number of characteristics in each turn. Among the features which they recorded were references to a set of 13 environmental and socioeconomic changes, which included any shift in the basic characteristics of the environment, local economy, or society (e.g., changes in ice, tourism, hazards or vegetation). These "change turns" were further analyzed for two key issues in the climate change literature: attribution and adaptation. We examined (1) whether the speaker attributed the mentioned local change to climate change and (2) whether the speaker described their past or future activities as adaptive responses to the mentioned change. In the second, computer-based type of analysis, we conducted keyword analysis, using a set of search terms related to the two frames. Aware of the existence of lexical gaps which could mean that people might be unfamiliar with, or reluctant to use, words and phrases such as "climate change," or even "community," we constructed sets of keywords for both frames. We counted occurrences of words like "adaptation," "resilience," "vulnerability" and "pollution" for the former and "neighbor," "district," "heritage," and "mayor" for the latter. Taken together, these two methodsone more qualitative, one more quantitative - complement each other, and provide understanding that might not come from the use of one alone (Stone 2001). See Online Resource B for a table of demographics and information on record types and a fuller description of the research methods.

\section{Perception of changes}

As shown in Fig. 1, the members of the communities discuss climate change impact frequently and consistently, mentioning shifts in a number of environmental features, many of them linked to livelihoods and well-being. They also mention socioeconomic changes. These findings are consistent with other ethnographic studies, which also report that local communities describe a number of climate change impacts, and include socioeconomic change along with environmental change. In other words, they do not find climate change hard to see.

More specifically, speakers commented on environmental and socioeconomic changes in approximately $13 \%$ of all turns. The most frequently mentioned change was ice $(\sim 5 \%$ of all turns, $\sim 38 \%$ of all change turns), the change which has the closest link to glacier retreat. The next four most frequently mentioned, in order, were water ( $\sim 3 \%$ of all turns, $\sim 24 \%$ of all change turns), socioeconomic conditions ( $\sim 3 \%$ of all turns, $\sim 23 \%$ of all change turns), weather ( $\sim 2 \%$ of all turns, $\sim 12 \%$ of all change turns), and agriculture ( $\sim 1 \%$ of all turns, $\sim 8 \%$ of all change turns). In these settings, water, particularly stream flow, is closely linked to glacier melt, and agriculture, in turn, is sensitive both to the availability of water for irrigation and to risks of flooding. The attention to socioeconomic change could be linked to climate change because of broad associations between natural and social worlds, as ethnographers have noted for other regions (Lipset 2011, 2013; Rudiak-Gould 2012; Sherpa 2014a), though it could also reflect the importance of socioeconomic change in many societies, whether affected by climate change or not.

These changes were followed in frequency by a number of other changes which residents mentioned less often: natural hazards, snow, the visual appearance of mountains, tourism, recreation, vegetation, wildlife, and hydropower. This relative ranking of changes is consistent across the three sites, though there is some variation in the absolute percentages for some of the changes. There are differences between the three conversation types. Ice, for example, is not mentioned in meetings but is referred to frequently in interviews (40\% of changes) and focus groups (38\% of changes). In meetings, however, socioeconomic conditions are mentioned more than three 


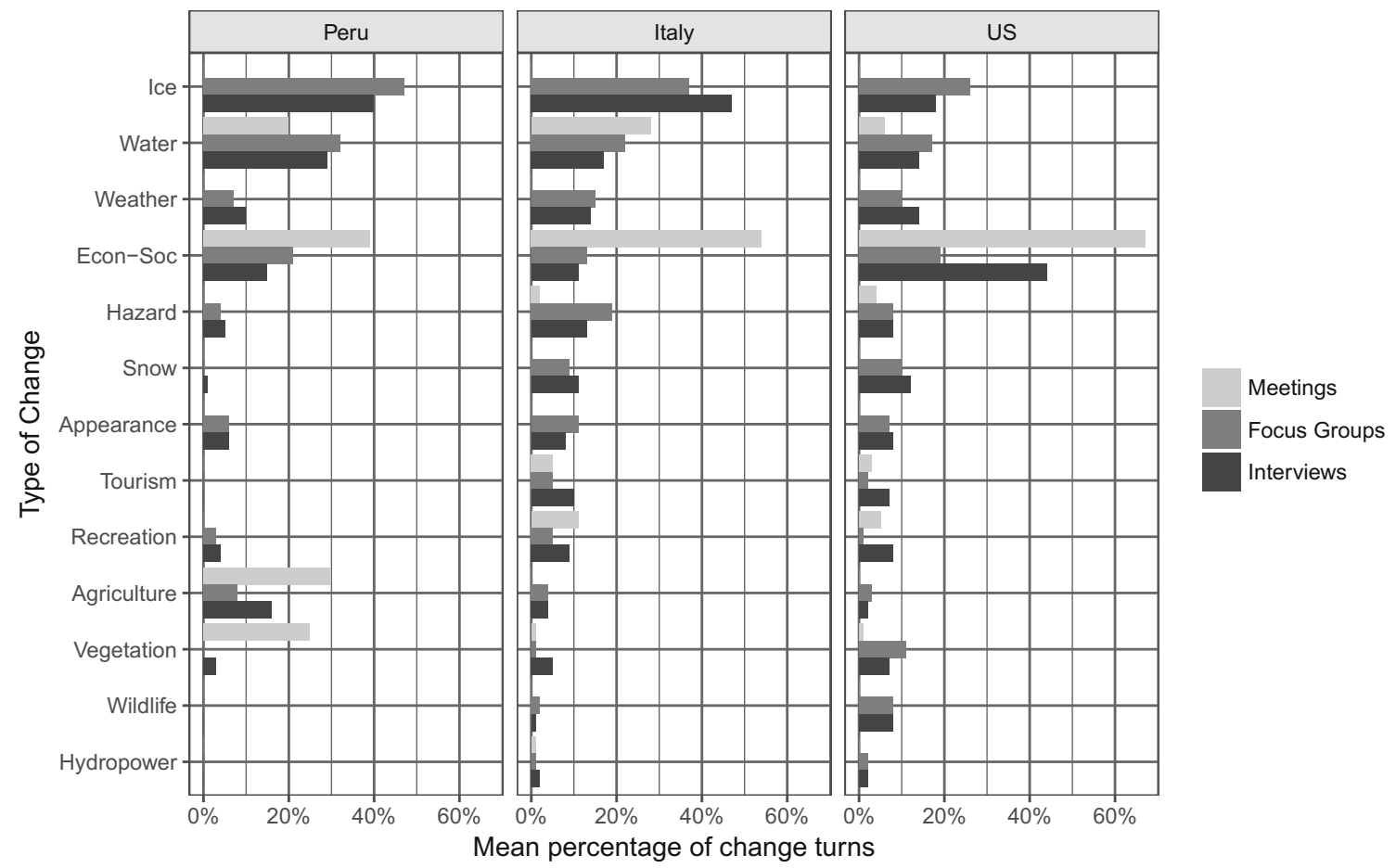

Fig. 1 Mean percentage of change turns by site and type of conversation

times as often ( $66 \%$ of changes) than in interviews $(21 \%$ of changes) and focus groups (20\% of changes). Figure 1 shows that differences are smaller for other types of changes across conversation types and sites. For details, see Online Resource C.

\section{Understanding of changes}

Though people recognize climate change impacts, they rarely link these change to climate change or offer adaptation as a response to address these changes. Overall, speakers attribute changes to climate change or global warming in only $4 \%$ of the turns in which they mention changes (see Fig. 2). Though this frequency is low for all three conversation types, it is particularly low for meetings, and it is also lower for Peru than for the USA or Italy. Further, in only 5\% of such change turns do they describe their actions as adaptive responses that they could perform to address changes (see Fig. 3). Speakers often described intended actions (e.g., raising electricity rates generated by the local hydropower facility in Italy) but did not link these responses to specific changes (e.g., lower water supply).

To assess how people in the communities understood the changes and responded to them, we examined the frequency with which people referenced the climate change and community frames. We found a significant difference in the frequency of appearance of the frames. Community frames were found in $4.83 \%$ of the turns, whereas climate change frames were only detected in $0.93 \%$ of the turns. Assignment to both frames was theoretically possible, but only observed in 20 out of a total of 28,466 turns, confirming the distinctiveness of the terms and frames.

We also examined the proportion of conversations in which the frames appeared at least once, recognizing that people can keep a frame in mind for a number of turns, without having to mention the terms in each turn. Here, too, the community frame was more common. It was mentioned in $78 \%$ of the conversations, while only $23 \%$ of all the conversations had at least one mention of the climate change frame. For details, see Online Resource D. The co-occurrence of both frames was observed in $17 \%$ of the conversations, also showing the distinctiveness of the terms and frames. Here, too, there were some differences between conversation types and sites for the climate change frame. As shown in Fig. 4, the terms associated with this frame appeared less often in meetings. Interestingly, there were fewer differences for the terms associated with the community frames, with no differences between the conversation types; for the sites, there was a tendency for the community frame to appear less often in the conversations in Italy, but this was a weaker relation.

To review this discussion, people in all three sites are keen observers of change. They refer to many changes, paying particular attention to three that are associated with climate change (ice, water and agriculture) as well as to socioeconomic change. However, they do not attribute these changes to climate change. In the conversations in which they participate, they draw on the community frame much more than the climate change frame. Though these patterns hold for all our 
Fig. 2 Changes turns as percentage of total turns indicating attribution to climate change
Attribute impact to climate change Do not attribute impact to climate change

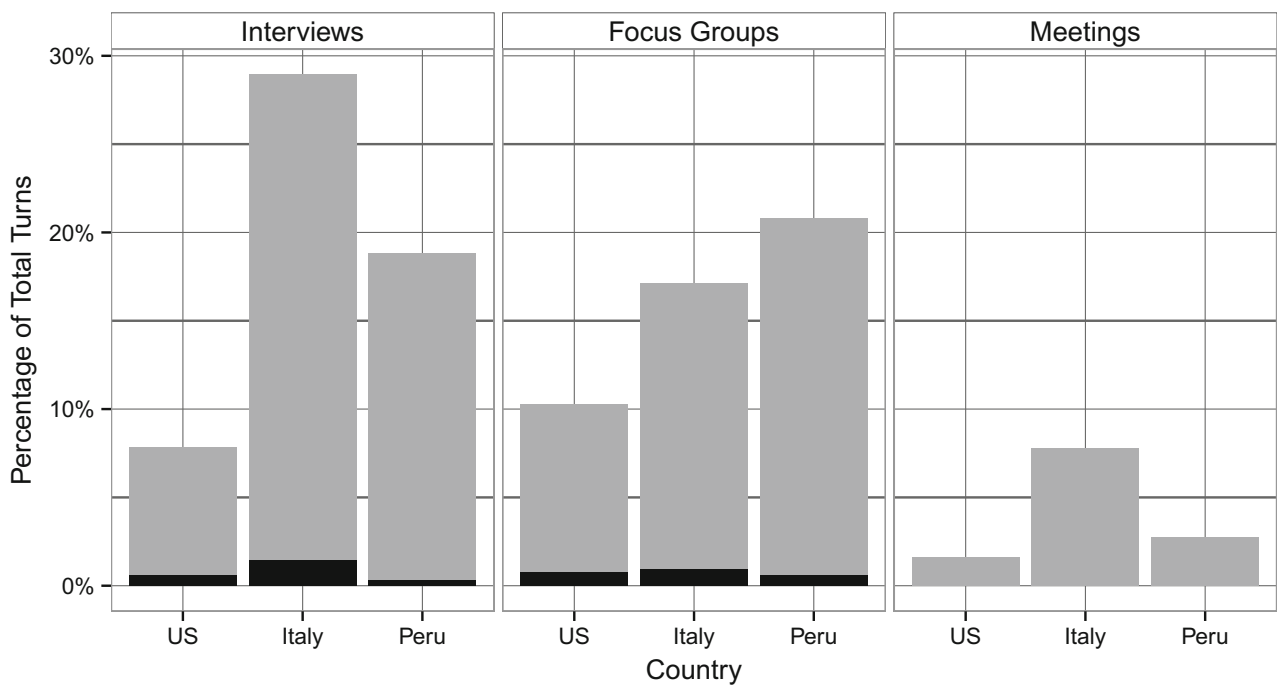

material, there are some differences for the meetings and for Peru; in these settings, the changes are listed in a slightly different order, and the community frame is even more dominant over the climate change frame.

\section{Discussion}

\section{Overview of climate change action}

We may now return to the questions raised in the first sections of this paper. Does longstanding direct exposure to climate impacts lead people to perceive climate change and to understand its nature and seriousness? Do these perceptions and understandings lead to actions to respond to climate change? We argue that our data suggest a revision of these questions, since the residents in all three cases are keenly aware of impacts related to climate change, and take steps to address these impacts. However, they understand these impacts and organize their responses through a community frame rather than a climate change frame. The community frame is central to their discussions of the actions, and it occurs more than five times as often in the records of the conversations in interviews, focus groups, and self-organized meetings.

These cases thus call into question what Findlater et al. (2018) call the perceive-predict-act approaches to climate change adaptation. Further, they show that the climate change frame may not be the only way to slay some of the most powerful dragons of inactionthe remoteness and uncertainty which surround climate change and thus limit adaptation efforts.
Fig. 3 Changes turns as percentage of total turns indicating discussion of adaptive responses
Discuss adaptive response to change $\square$ Do not discuss adaptive response to change

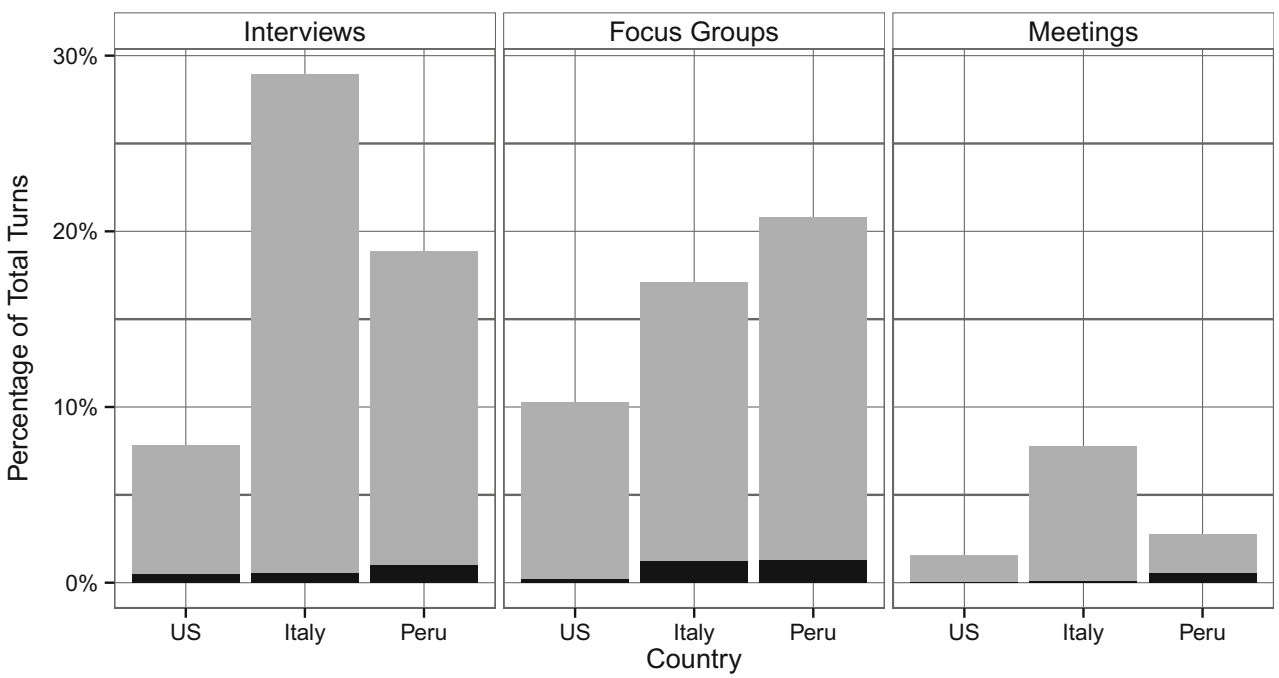


Fig. 4 Proportion of records which mention specific frames by site and type of conversation
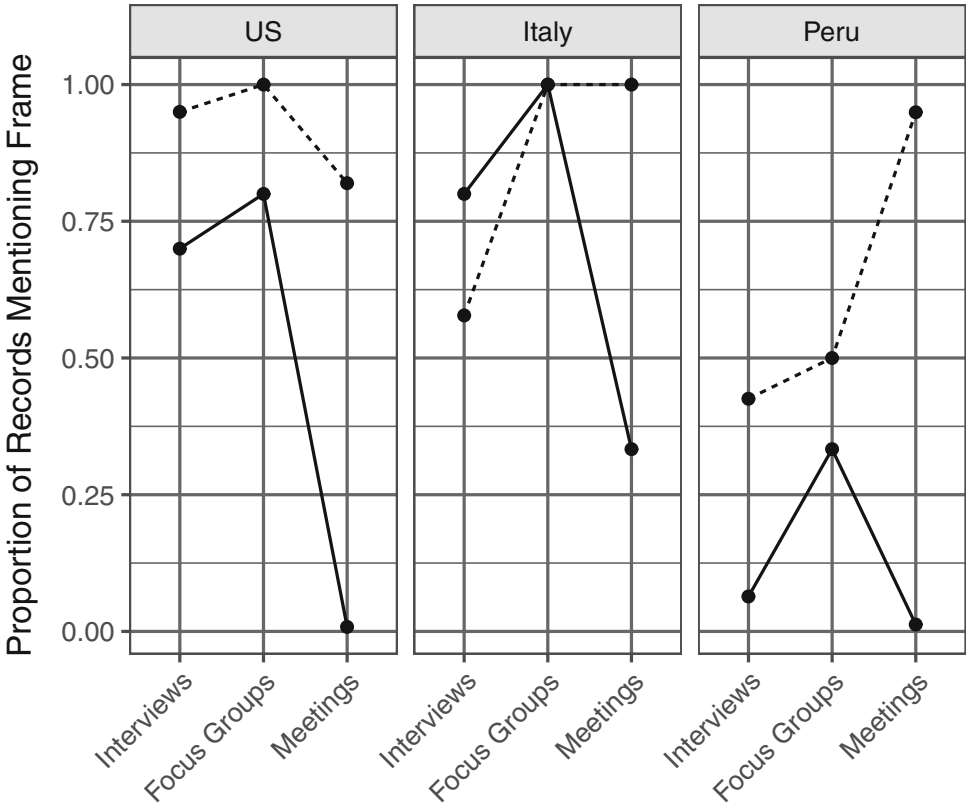

Frame

- Climate Change

.... Community

\section{Interacting frames to account for environmental change}

In all three communities, people perceive climate change impacts, along with socioeconomic impacts, and they act on these impacts, but they do not link the two with predictions based on the climate change frame. In this way, these cases can serve to open a discussion on the issue of belief in climate change. A number of studies about climate change are organized around the question of belief and its opposite, variously termed non-belief, denial, or skepticism. For some, populations can be divided into believers and non-believers (Dunlap 2013), while others offer a slightly wider array of possibilities, such as additional categories of partial belief and lacking opinion (Hamilton et al. 2015) or placing several intermediate points between full belief and full non-belief (Leiserowitz et al. 2012).

Like a number of other anthropologists who have studied climate change, we find that perceptions and understandings of climate change are not based simply on the degree of acceptance of the climate change frame, but rather on the patterns of interaction between it and pre-existing frames. Though each of these patterns is complex, some key features of each can be found: rejection of the new frame in the Bangladeshi case, a cautious coexistence between old and new frames as in Papua New Guinea, or hybridity, whether hesitant as in Siberia or extensive as in the Marshall Islands. The Nepali case shows greater internal variability than the others, with patterns of acceptance of the two frames differing by gender, age, and location. The three cases we examine represent another alternative, which we call inattention: local people are aware of the climate change frame but do not mention it often. Moreover, we see internal variability, but along different lines than in the Nepali case: the use of the frames varies, not by the characteristics of individuals, but by social context.

In our cases, we have observed very low levels of cooccurrence of the two frames in turns and conversations in this study. This pattern reflects the characteristic operation of frames. As discussed earlier, they filter information, structuring narratives in ways that allow courses of action to be selected. They therefore do not always lend themselves to a mixand-match approach, which could undercut their ability to focus attention. We note as well that the Pacific cases, where the fullest instances of combination of the two frames are found, reflect highly specific conditions: small societies, heavy presence of organizations and media which present the climate change frame, and high levels of climate adaptation finance, reaching over $\$ 400$ per capita per year in some small island developing states for the period 2010-2015 (Weiler et al. 2018).

\section{The role of social context in the use of frames}

In each of the three cases which we have studied, the use of the climate change and community frames shows a similar pattern of variability. People draw on both, though to different extents. When in interviews or focus groups, they draw more often on the community frame than the climate change frame; when in meetings, this tendency is even stronger. Moreover, this shift does not reflect variations in the use of the community change frame, which is similar across the three types of conversation, but rather in the use of the climate change frame, which they mention significantly less often in meetings. 
We suggest that this distinctiveness of the meetings may result from two related sources. The first is an interviewer effect (Kreuter 2008); the researcher may be seen as a representative of scientific and policy frameworks which emphasize climate change, even though speakers were prompted to discuss only more general changes in local mountains. In this way, the field researcher's presence stimulated more frequent mentions of this frame than were found in meetings. This view bears some similarity to other ethnographic accounts. Sherpa's discussion of Nepal indicates that the young men who are exposed to the climate change frame through NGO staff and foreign trekkers retain this frame even in the absence of these outsiders, while Khan's account of Bangladesh suggests that villagers engage with the climate change frame only when the outsiders are physically present, avoiding it when they are absent. As indicated earlier, engagement with a frame can rest not only on belief in the propositions it contains and on the evidence it offers for them but also on engagement with the sources of those propositions. These sources are absent from meetings.

The second possible source is the contrast between the purposes and expectations in the different types of conversations. In interviews and focus groups, speakers focus on describing their experiences to researchers, and thus, general explanatory frameworks such as climate change may come to mind to describe changes. By contrast, community meetings tend to be action-oriented. Local residents focus on ongoing community matters that can be addressed in the short run. Similarly, changes to which the community can more easily construct responses (water, socioeconomic conditions) are mentioned more frequently than in interviews and focus groups.

\section{The significance of the community frame}

The three conversation types, where the community frame predominates, are not only research methods, but concrete social settings as well. Local people sometimes speak oneon-one with outsiders, like the interviews, or have group meetings, like the focus groups. They can come to formulate and enact plans for action in all three settings. Their talk in community meetings - the setting in which they rely most strongly on the community frame- shows that it is possible to take action to address climate change without explicitly speaking of climate itself. In this way, these actions come close to examples of "autonomous adaptation," defined in the Glossary of Working Group II of the Sixth Assessment Report as "adaptation in response to experienced climate and its effects, without planning explicitly or consciously focused on addressing climate change." (Agard et al. 2014: 1759). We note, though, that this definition is a negative one, resting on the absence of the climate change frame; our discussion looks as well to a positive element, the presence of the community frame.
Examined from the perspective of climate communication, it could be argued that the community frame is more effective than the climate change frame because it emphasizes "cobenefits" of adaptation, particularly improving socioeconomic conditions (Bain et al. 2016), as can be seen in the efforts in Peru to protect local streams from appropriation by distrusted outsiders or in Italy to retain control over local energy production. Alternatively, the effectiveness of the community frame could be located in its emphasis of place attachment, a potential motivator of action, as seen in the appeal of local festivals in Washington State.

More simply, the fact that local people draw on the community frame points to their familiarity with it and their acceptance of it, characteristics which allow them to base action on it. All three local communities undertake actions which reduce the impacts of glacier retreat-including new forms of tourism, not based on snow and ice, in the USA; new sources of energy, not reliant on glacier-dependent streamflow in Italy; and more efficiency transport of water for irrigation and domestic use, in a context of reduced streamflow, in Peru. However, they discuss these projects through a community frame. Rather than speaking directly of glaciers or of climate change, they emphasize the importance of secure livelihoods and of intergenerational continuity. They also speak of community autonomy, opposing government intervention in Peru and Italy and emphasizing self-reliance in the USA. They draw on community traditions and cultural heritage, as a focus for new festivals in the USA, as a reason to support biomass fuels in Italy, and as a basis for organizing water use in Peru.

In sum, these mountain residents are well aware of climate change impacts on ice, water, and many other aspects of their lives, including social and economic conditions, and they take actions to address these impacts. However, they treat the climate change frame with inattention; though they are aware of it, they do not speak of it very much. The community frame, which draws on their social ties and shared understandings of their histories and their futures, serves them to understand their world and to take actions to maintain it in the face of threats.

We suggest that this research calls into question the view that an engagement with climate change frames is a necessary precursor to taking action on climate change (McCright et al. 2016). Where the perceive-predict-act model suggests that climate change action comes more effectively when actors see climate change and understand its future impacts, these cases indicate a distinct pathway, based on a different frame, to action on climate change impacts. As an alternative to viewing the residents of these frontline communities in negative terms, casting them as dubious or skeptical about climate change, we propose that that they can be viewed in positive terms, exploring the ways that they have drawn on the community frames. In this way, we join those who call for climate communication to be a genuine dialog, rather than an effort to 
find locally appropriate sugarcoatings to the necessary, if bitter, climate change pill (Barnes et al. 2013; Pearce et al. 2015). Instead of considering what could be gained if populations like these in mountains took more seriously what others say about climate change, we have sought to document what could be gained if others took more seriously what mountain populations say about community and what they do about glacier retreat.

Open Access This article is distributed under the terms of the Creative Commons Attribution 4.0 International License (http:// creativecommons.org/licenses/by/4.0/), which permits unrestricted use, distribution, and reproduction in any medium, provided you give appropriate credit to the original author(s) and the source, provide a link to the Creative Commons license, and indicate if changes were made.

\section{References}

Agard J, Schipper ELF, Birkmann K, Campos M, Dubeux C, Nojiri Y, Olsson L, Osman-Elasha B, Pelling M, Prather MJ, Rivera-Ferre MG, Ruppel OC, Sallenger A, Smith KR, St. Clair AL (2014) Glossary. In: Barros VR, Field CB., Dokken DJ, Mastrandrea MA, Mach KJ, , Bilir TA, )Chatterjee M, Ebi KL, Estrada YO, Genova RD, Girma B, Kissel ES, Levy AN, MacCracken S, Mastrandrea PR, White LL (eds) Climate change 2014: impacts, adaptation, and vulnerability. Part B: regional aspects. Contribution of Working Group II to the Fifth Assessment Report of the Intergovernmental Panel on Climate Change. Cambridge Cambridge University Press, pp. $1757-1776$

Arbuckle JG, Prokopy LS, Haigh T, Hobbs J, Knoot T, Knutson C, Loy A, Mase AS, McGuire J, Morton LW, Tyndall J (2013) Climate change beliefs, concerns, and attitudes toward adaptation and mitigation among farmers in the Midwestern United States. Clim Chang 117:943-950. https://doi.org/10.1007/s10584-013-0707-6

Bain PG, Milfont TL, Kashima Y, Bilewicz M, Doron G, Garðarsdóttir RB, Gouveia VV, Guan Y, Johansson LO, Pasquali C, CorralVerdugo V (2016) Co-benefits of addressing climate change can motivate action around the world. Nat Clim Chang 6:154-157. https://doi.org/10.1038/nclimate2814

Barnes J, Dove M, Lahsen M, Mathews A, McElwee P, McIntosh R, Moore F, O'Reilly J, Orlove B, Puri R, Weiss H (2013) Contribution of anthropology to the study of climate change. Nat Clim Chang 3:541-544. https://doi.org/10.1038/nclimate177

Benoit K, Laver M (2007) Estimating party policy positions: comparing expert surveys and hand-coded content analysis. Electoral Stud 26(1):90-107. https://doi.org/10.1016/j.electstud.2006.04.008

Bobfiglio G (2014) Las municipalidades de centro poblado en el Peru. Instituto de Estudios Peruanos, Lima

Crate SA (2008) Gone the bull of winter? Grappling with the cultural implications of and anthropology's role(s) in global climate change. Curr Anthro 49:569-595. https://doi.org/10.1086/529543

Dunlap RE (2013) Climate change skepticism and denial: an introduction. Am Behav Sci 57:691-698. https://doi.org/10.1177/ 0002764213477097

Enfield NJ (2017) How we talk: the inner workings of conversation. Basic Books, New York

Findlater KM, Donner SD, Satterfield T, Kandlikar M (2018) Integration anxiety: the cognitive isolation of climate change. Glob Environ Chang 50:178-189. https://doi.org/10.1016/j.gloenvcha.2018.02. 010
Fløttum K, Gjerstad U (2017) Narratives in climate change discourse. WIREs Clim Change 8:e429. https://doi.org/10.1002/wcc.429

Gagné K (2019) Caring for glaciers: land, animals, and humanity in the Himalayas. University of Washington Press, Seattle

Gifford R (2011) The dragons of inaction: psychological barriers that limit climate change mitigation and adaptation. Am Psychol 66: 290-302. https://doi.org/10.1037/a0023566

Goffman E (1974) Frame analysis: an essay on the organization of experience. Harvard University Press, Cambridge

Guy S, Kashima Y, Walker I, O’Neill S (2014) Investigating the effects of knowledge and ideology on climate change beliefs. Eur J Soc Psychol 44:421-429. https://doi.org/10.1002/ejsp.2039

Hamilton LC, Hartter J, Lemcke-Stampone M, Moore DW, Safford TG (2015) Tracking public beliefs about anthropogenic climate change. PLoS One 10(9):e0138208. https://doi.org/10.1371/journal.pone. 0138208

Khan N (2014a) Dogs and humans and what earth can be: filaments of Muslim ecological thought. Hau: J Ethnographic Theory 4:245264. https://doi.org/10.14318/hau4.3.015

Khan N (2014b) The death of nature in the era of global warming. In: Chatterji R (ed) Wording the world: Veena Das and scenes of inheritance. Forms of living. Fordham University Press, Bronx, NY, pp 288-299. https://doi.org/10.5422/fordham/9780823261857.003. 0016

Kreuter F (2008) Interviewer effects. In: Lavrakas PJ (ed) Encyclopedia of survey research methods. Sage, Thousand Oaks, CA, pp 370 372. https://doi.org/10.4135/9781412963947.n242

Leiserowitz A, Maibach E, Roser-Renouf C, Hmielowski J (2012) Global warming's six Americas, March 2012 \& Nov. 2011. Yale University and George Mason University, New Haven, CT http://environment. yale.edu/climate/files/Six-Americas-March-2012.pdf. Accessed 12 Dec 2018

Lipset D (2011) The tides: masculinity and climate change in coastal Papua New Guinea. J R Anthropol Inst 17:20-43. https://doi.org/ 10.1111/j.1467-9655.2010.01667.x

Lipset D (2013) The new state of nature: rising sea-levels, climate justice, and community-based adaptation in Papua New Guinea (20032011). Conserv Soc 11:144-158. https://doi.org/10.4103/09724923.115726

McCright AM, Charters M, Dentzman K, Dietz T (2016) Examining the effectiveness of climate change frames in the face of a climate change denial counter-frame. Top Cogn Sci 8:76-97. https://doi. org/10.1111/tops.12171

McQuaid K, Vanderbeck RM, Valentine G, Liu C, Chen L, Zhang M, Diprose K (2018) Urban climate change, livelihood vulnerability and narratives of generational responsibility in Jinja, Uganda. Africa 88:11-37. https://doi.org/10.1017/s0001972017000547

Mendoza M (2018) The Patagonian sublime: the green economy and post-neoliberal politics. Rutgers University Press, New Brunswick, NJ

Pearce W, Brown B, Nerlich B, Koteyko N (2015) Communicating climate change: conduits, content, and consensus. Wiley Interdiscip Rev-Clim Chang 6:613-626. https://doi.org/10.1002/wcc.366

Pidgeon N and Fischhoff B (2011) The role of social and decision sciences in communicating uncertain climate risks. Nat Clim Change 1: 35-41. https://doi.org/10.1038/nclimate1080

Rasmussen BM (2015) Andean waterways: resource politics in highland Peru. University of Washington Press, Seattle

Reynols W, Bostrom A, Read D, Morgan MG (2010) Now What Do People Know About Global Climate Change? Survey Studies of Educated Laypeople. Risk Anal 30:1520-1538. https://doi.org/10. $1111 / j .1539-6924.2010 .01448 . x$

Rudiak-Gould P (2012) Promiscuous corroboration and climate change translation: a case study from the Marshall Islands. Glob Environ Chang 22:46-54. https://doi.org/10.1016/j.gloenvcha.2011.09.011 
Sherpa PY (2014a) Climate change, perceptions, and social heterogeneity in Pharak, Mount Everest Region of Nepal. Hum Organ 73:153161. https://doi.org/10.17730/humo.73.2.94q43152111733t6

Sherpa PY (2014b) Flooded with memories in Nepal. GlacierHub. http:// glacierhub.org/2014/09/03/flooded-with-memories-in-nepal/. Accessed 10 June 2018

Stone P (2001) Content analysis. In: Rhonda JV, Montgomery RJV (eds) Encyclopedia of sociology, vol 1, 2nd edn. Macmillan Reference, New York, NY, pp 417-422

Tversky A, Kahneman D (1981) The framing of decisions and the psychology of choice. Science 211:453-458. https://doi.org/10.1126/ science. 7455683
Weber EU, Stern PC (2011) Public understanding of climate change in the United States. Am Psychol 66:315-328. https://doi.org/10.1037/ a0023253

Weiler F, Klöck C, Dornan M (2018) Vulnerability, good governance, or donor interests? The allocation of aid for climate change adaptation. World Dev 104:65-77. https://doi.org/10.1016/j.worlddev.2017.11. 001

Publisher's note Springer Nature remains neutral with regard to jurisdictional claims in published maps and institutional affiliations. 